\title{
Resveratrol mitigates isoflurane-induced neuroapoptosis by inhibiting the activation of the Akt-regulated mitochondrial apoptotic signaling pathway
}

\author{
TAO BAI, DAO-SONG DONG and LING PEI
}

Department of Anaesthesiology, the First Hospital of China Medical University, Shenyang, Liaoning 110001, P.R. China

Received May 21, 2013; Accepted July 26, 2013

DOI: $10.3892 / \mathrm{ijmm} .2013 .1464$

\begin{abstract}
The inhalation anesthetic, isoflurane, induces learning and memory impairment. Mitochondrial dysfunction and oxidative stress are thought to play important roles in isoflurane-induced neuroapoptosis. In this study, we treated neuronal cells with isoflurane for $6 \mathrm{~h}$. We found that isoflurane induced the opening of mitochondrial permeability transition pores, increased the levels of reactive oxygen species and the activation of caspase-3, and decreased the mitochondrial membrane potential and the intracellular calcium ion concentration. Resveratrol (RESV; trans-3,5,4'-trihydroxystilbene), a naturally occurring phytoalexin, is found at high concentrations in the skin of red grapes and red wine and has been demonstrated to have anti-infective, antioxidant and cardioprotective functions. Our findings demonstrated that the neuroprotective effects of RESV were independent on its direct radical scavenging properties. Following treatment of the cells with various concentrations of RESV, we found that RESV induced the expression of mitochondrial superoxide dismutase and catalase activity, and reduced mitochondrial oxidative stress and damage. The data from the present study demonstrate that RESV effectively protects neuronal cells from isofluraneinduced cytotoxicity by activating the Akt signaling pathway.
\end{abstract}

\section{Introduction}

An estimated 200 million patients worldwide undergo anesthesia and surgery each year $(1,2)$. Previous studies have reported that subanesthetic exposure to individual anesthetic drugs, including ketamine (3), propofol (4) and sevoflurane (5), triggers a significant neuroapoptotic response in the infant rodent brain. Likewise, isoflurane alone causes cell damage in various neuronal and non-neuronal tissues and cells $(6,7)$. The anesthetic action of isoflurane is thought to be mediated by

Correspondence to: Dr Tao Bai, Department of Anaesthesiology, the First Hospital of China Medical University, 155 Nanjing North Street, Heping, Shenyang, Liaoning 110001, P.R. China

E-mail: baitao720418@163.com

Key words: resveratrol, isoflurane, neuroapoptosis, AKT, reactive oxygen species multiple mechanisms, including actions on $\mathrm{GABA}_{\mathrm{A}}$, glycine and glutamate receptors and potassium channels (8-10). Isoflurane is also known to exert a depolarizing action on neuronal mitochondria (11). Isoflurane induces caspase activation and apoptosis through the mitochondrial-dependent apoptotic pathway (12).

Resveratrol (RESV; trans-3,5,4'-trihydroxystilbene), a polyhydroxyphenolic antioxidant, was first isolated in 1940 as an ingredient of the roots of white hellebore (13) and since then it has been isolated from a variety of plant species, including grapes (14). The trans-isomeric form of RESV is the steady form and mediates a broad-spectrum of beneficial health effects, including anti-infective, antioxidant and cardioprotective functions (15). In multiple models of neurological injury, RESV has demonstrated efficacy in reducing neuropathological and behavioral sequelae, such as stroke $(16,17)$, spinal cord injury $(18,19)$ and Huntington's disease $(20)$. Thus, it is important to obtain a better understanding of the mechanisms behind the neuroprotective effects of RESV in brain cells.

To our knowledge, there are no related reports to date on the role of RESV in isoflurane-induced neuroapoptosis. In this study, we confirm and extend previous findings and demonstrate the neuroprotective effects of RESV. Importantly, the mechanism(s) of action of RESV were determined by western blot analysis to determine the expression of apoptosis-related molecules, such as caspase-3, -8 and -9 .

\section{Materials and methods}

Cell culture and treatment. All experiments with animals were performed according to the guidelines of our University Ethics Committee. Neuronal cells derived from the cerebral neocortex were harvested from 16-day-old embryonic mice by caesarean section from pregnant BALB/c mice. The cells $\left(5 \times 10^{5}\right)$ were plated on 24-well plates pre-coated with poly-L-lysine (Sigma Chemical, St. Louis, MO, USA) and the cultures were maintained at $37^{\circ} \mathrm{C}$ in a $5 \%(\mathrm{v} / \mathrm{v}) \mathrm{CO}_{2}$ incubator and supplemented with neurobasal medium supplemented with B27 (X1) and glutamine $(25 \mathrm{mM})$. Neuronal cell cultures were ready to use on day $7 . \mathrm{O}_{2}(21 \%), \mathrm{CO}_{2}(5 \%)$ and isoflurane $(2 \%)$ were delivered from an anesthesia machine to a sealed plastic box. A Datex infrared gas analyzer (Puritan-Bennett, Tewksbury, MA, USA) was used to continuously monitor the delivered carbon dioxide, oxygen and isoflurane concentrations. 
Drugs. RESV (Sigma Chemical) was dissolved in 7:3 saline (0.9 \% NaCl):solutol (BASF Corp., Wyandotte, MI, USA). Butin was purchased from Wako Pure Chemical Industries, Ltd. (Tokyo, Japan) and dissolved in dimethylsulfoxide (DMSO); the final concentration of DMSO did not exceed $0.02 \%$.

Experimental design. The cells were divided into 7 groups as follows: group 1, control; group 2, $2 \%$ isoflurane for $6 \mathrm{~h}$; group 3, RESV $50 \mu \mathrm{M}$ for $24 \mathrm{~h}+2 \%$ isoflurane for $6 \mathrm{~h}$; group 4 , RESV $100 \mu \mathrm{M}$ for $24 \mathrm{~h}+2 \%$ isoflurane for $6 \mathrm{~h}$; group 5 , RESV $200 \mu \mathrm{M}$ for $24 \mathrm{~h}+2 \%$ isoflurane for $6 \mathrm{~h}$; group 6 , butin $10 \mu \mathrm{g} / \mathrm{ml}$ for $24 \mathrm{~h}+2 \%$ isoflurane for $6 \mathrm{~h}$; group 7, RESV $200 \mu \mathrm{M}$ for $24 \mathrm{~h}+$ siRNA AKT for $24 \mathrm{~h}+2 \%$ isoflurane for $6 \mathrm{~h}$.

3-(4,5-Dimethylthiazol-2-yl)-2,5-diphenyltetrazolium bromide (MTT) assay. To investigate the protective effects of RESV on isoflurane-induced neuronal death, MTT assay was used. MTT $(10 \mu 1$, at $5 \mathrm{mg} / \mathrm{ml})$ was added to each well at a final concentration of $500 \mu \mathrm{g} / \mathrm{ml}$, and the mixture was further incubated for $1 \mathrm{~h}$ at $37^{\circ} \mathrm{C}$ and the liquid in the wells was removed thereafter. DMSO (100 $\mu \mathrm{l})$ was then added to each well and the absorbance was read using a UV Max microplate reader (Molecular Devices, Palo Alto, CA, USA) at $560 \mathrm{~nm}$.

TUNEL assay. For apoptosis detection, the cells were washed in PBS, fixed, permeabilized and subjected to TUNEL labeling using an in situ Cell Death Detection kit (KeyGen, Nanjing, China) according to the manufacturer's instructions. Following counterstaining with DAPI $(1 \mu \mathrm{g} / \mathrm{ml})$, photographic images were acquired using an Olympus CX71 fluorescence microscope (Olympus, Tokyo, Japan). TUNEL-positive nuclei were stained green and all other nuclei were stained blue as previously described $(21,22)$.

Comet assay. A comet assay was performed to assess oxidative DNA damage $(23,24)$. The cell pellet $\left(1.5 \times 10^{5}\right.$ cells $)$ was mixed with $100 \mu 1$ of $0.5 \%$ low melting agarose (LMA) at $39^{\circ} \mathrm{C}$ and spread on a fully frosted microscopic slide that was pre-coated with $200 \mu \mathrm{l}$ of $1 \%$ normal melting agarose (NMA). Following solidification of the agarose, the slide was covered with an additional $75 \mu \mathrm{l}$ of $0.5 \%$ LMA and then immersed in lysis solution (2.5 M NaCl, $100 \mathrm{mM}$ EDTA, $10 \mathrm{mM}$ Tris, $1 \%$ Trion X-100 and 10\% DMSO; $\mathrm{pH} 10.0$ ) for $1 \mathrm{~h}$ at $4^{\circ} \mathrm{C}$. The slides were then placed in a gel electrophoresis apparatus containing $300 \mathrm{mM} \mathrm{NaOH}$ and $10 \mathrm{mM}$ EDTA (pH 13.0) for 40 min to allow DNA unwinding and the expression of the alkali-labile damage. Following electrophoresis, the slides were washed 3 times for $5 \mathrm{~min}$ at $4^{\circ} \mathrm{C}$ in a neutralizing buffer (0.4 M Tris, $\mathrm{pH} 7.5$ ) and then stained with $75 \mu \mathrm{l}$ of ethidium bromide $(20 \mu \mathrm{g} / \mathrm{ml})$. The slides were observed under an Olympus CX71 fluorescence microscope.

Cell apoptosis assay. Apoptosis was determined using an Apoptosis Detection kit (KeyGen). Briefly, the cells were collected, washed twice in ice-cold PBS and then resuspended in binding buffer at a density of $1 \times 10^{6}$ cells $/ \mathrm{ml}$. The treated cells were incubated with fluorescein-labeled Annexin V and propidium iodide (PI) for $20 \mathrm{~min}$. Following the labeling reaction, the expression of Annexin at the cell surface was analyzed by a FACSCalibur (Model FACSC 420; BD Biosciences, Baltimore, MD, USA). Data were analyzed using CellQuest software from BD Biosciences.

Determination of mitochondrial membrane potential (MMP). MMP was analyzed using the fluorescent dye, 5,5',6,6'-tetrachloro-1,1',3,3'-tetraethylbenzimidazolycarbocyanine iodide (JC-1), following the manufacturer's instructions (KeyGen). Briefly, the cells were plated in a 6-well culture plate. Following treatment for $24 \mathrm{~h}$, the cells were washed twice with PBS, harvested and incubated with $20 \mathrm{nM} \mathrm{JC}-1$ for $30 \mathrm{~min}$ in the dark. MMP was then analyzed using a FACSCalibur, as described above.

Flow cytometric analysis of mitochondrial permeability transition pore (mPTP) opening. The opening of MPTPs was determined by flow cytometry (FCM), using the MitoProbe ${ }^{\mathrm{TM}}$ Transition Pore Assay kit (Invitrogen, Carlsbad, CA, USA). Under normal conditions, the non-fluorescent acetoxymethyl (AM) ester of calcein dye (calcein AM) and cobalt enters the cell. The AM groups are cleaved from calcein via non-specific esterase and calcein can then show fluorescence signals in the cytosol and mitochondria. Cobalt quenches the cytosolic calcein signal. However, cobalt cannot enter healthy mitochondria freely and therefore cannot quench the mitochondrial calcein signal. When the opening of mPTPs occurs, cobalt enters through the pores and subsequently quenches the mitochondrial calcein signal. FCM was used to detect the number of cells that exhibited quenched calcein signals inside the mitochondria. The location of the curves indicates the numbers of such cells, which suggests the opening of mPTPs (25).

Quantification of cellular reactive oxygen species (ROS). The levels of cellular ROS were quantified according to a previously described method (26). Briefly, the cells $\left(5 \times 10^{5}\right)$ were cultured in 12-well tissue culture plates overnight and then co-treated with drugs and 2',7'-dichlorofluorescein diacetate (DCF-DA), a ROS-sensitive dye. Following treatment with the drugs, the cells were harvested and suspended in PBS. Relative fluorescence intensities of the cells were quantified using a FACSCalibur, as described above.

Catalase (CAT) assay. CAT activity was assayed using the method developed by Aebi (27) which is based on the disappearance of hydrogen peroxide $\left(\mathrm{H}_{2} \mathrm{O}_{2}\right)$ at $240 \mathrm{~nm}$. One unit was defined as $1 \mu \mathrm{mol}$ of $\mathrm{H}_{2} \mathrm{O}_{2}$ consumed per min, and the specific activity was reported as $\mathrm{U} / \mathrm{mg} /$ protein.

Superoxide dismutase (SOD) assay. The mitochondria and cytosol were fractionated using the Mitochondria/Cytosol Fractionation kit (BioVision, Sheffield, UK). The amount of proteins was determined using the Bio-Rad Protein Assay (BioRad, Hercules, CA, USA). SOD activity was determined using the SOD Activity Assay kit (BioVision). The relative SOD activity was normalized according to the protein content and shown as a percentage of SOD activity present in the control cells.

Measurement of adenosine triphosphate (ATP) levels. According to the instructions provided by the company, ATP assays were conducted using either the ATPlite Assay 
Table I. Antibodies used in western blot analysis.

\begin{tabular}{llll}
\hline Protein & Producer & Catalog no. & Dilution \\
\hline AKT & Santa Cruz & sc-377457 & $1: 200$ \\
p-AKT & Santa Cruz & sc-135650 & $1: 200$ \\
Bax & Santa Cruz & sc-7480 & $1: 200$ \\
Bcl-xL & Santa Cruz & sc-8392 & $1: 200$ \\
Bcl-2 & Santa Cruz & sc-783 & $1: 200$ \\
p-Bcl-2 & Santa Cruz & sc-16323 & $1: 200$ \\
Caspase-9 & Santa Cruz & sc-56076 & $1: 200$ \\
Caspase-3 & Santa Cruz & sc-136219 & $1: 200$ \\
$\beta$-actin & Santa Cruz & sc-47778 & $1: 1,000$ \\
\hline
\end{tabular}

${ }^{\text {aS }}$ anta Cruz, CA, USA.

(PerkinElmer, Waltham, MA, USA) or the ATP Determination kit (Invitrogen).

Intracellular $\mathrm{Ca}^{2+}$ measurement. The $\mathrm{Ca}^{2+}$ fluorescence intensity in the cells was also measured using a flow cytometer (Beckman Coulter, Brea, CA, USA). The cells in 6-well plates were digested with $0.05 \%$ trypsin-EDTA, incubated with $10 \mu \mathrm{M}$ Fluo-4/AM ester for $30 \mathrm{~min}$ at $37^{\circ} \mathrm{C}$, centrifuged and washed by PBS 3 times. The cells were diluted to $5 \times 10^{5}$ cell suspension with fixation solution for FCM. For each experiment experiment, 5,000 random cells were selected by FCM to analyze the fluorescence intensity.

Measurement of caspase-3, -8 and -9 activities. Caspase activity was measured using a Colorimetric Assay kit according to the manufacturer's instructions. After harvesting, the cells were washed in ice-cold PBS and lysed; proteins were extracted and stored at $-80^{\circ} \mathrm{C}$ until use. Cell lysate $(20 \mu \mathrm{l})$ was added to a buffer containing a p-nitroaniline (pNA)-conjugated substrate $(80 \mu \mathrm{l})$ for caspase-3 (Ac-DEVD-pNA; KGA203), -8 (Ac-IETD-pNA; KGA302), or -9 (LEHD-pNA; KGA402; all from KeyGen). Incubation was performed at $37^{\circ} \mathrm{C}$ with shaking (500 rpm for $1 \mathrm{~min}$ ) and then at room temperature for $2 \mathrm{~h}$. The released pNA in each well was measured using a plate-reading luminometer (Thermo Scientific, Beijing, China).

Immunoblotting. Protein extracts were analyzed by western blot analysis using the antibodies listed in Table I. Cell extracts obtained in Laemmli buffer were resolved on SDS-PAGE, followed by electrotransfer onto nitrocellulose membranes. Following a blocking step in 5\% milk in Tween-TBS, the membranes were incubated with primary and secondary antibodies. The membranes were then developed and visualized by enhanced chemiluminescence (ECL) (Pierce Antibodies; Thermo Fisher Scientific, Inc., Rockford, IL, USA).

Statistical analysis. The statistical significance of the differences between the control and drug-treated groups was evaluated using the Student's t-test and differences were considered statistically significant at P-values $<0.05$. Analysis of the data was performed using GraphPad Prism 4 software (GraphPad Software, Inc., San Diego, CA, USA).

\section{Results}

Isoflurane induces apoptosis in neuronal cells. To determine whether isoflurane induces apoptosis in neuronal cells, the cells were treated with $2 \%$ isoflurane for $6 \mathrm{~h}$. As shown in Fig. 1A, the proliferation rate of the neuronal cells was inhibited by isoflurane $(\mathrm{P}<0.05)$. The proliferation of the neuronal cells was inhibited by isoflurane. The isoflurane-treated cells with damaged DNA displayed high migration of DNA fragments from the nucleus, forming a tail in comet form (Fig. 1B). TUNEL assay confirmed that the number of apoptotic cells in the isoflurane-treated groups was significantly higher than that in the untreated group (Fig. 1C). To detect apoptotic cells quantitatively, Annexin V-FITC and PI double staining was performed. In the cells treated with isoflurane, the apoptotic ratio was 8-10-fold higher than that in the untreated cells $(\mathrm{P}<0.05)$ (Fig. 1D). As caspase-3 activation is one of the final steps of cellular apoptosis (28), we assessed the effects of isoflurane on the activation of caspase- $3,-8$ and -9 by colorimetric assay and western blot analysis. The activity of caspase-3, - 8 and -9 was significantly increased in the isoflurane-treated cells compared with the untreated cells (Figs. 1E and 3).

Isoflurane induces apoptosis in neuronal cells by destroying the mitochondria. As shown in Fig. 2A, the ratio of red/green in the neuronal cells $(2.3 \%$ green, $97.7 \%$ red) was reversed following treatment with isoflurane (73.8\% green, $26.2 \%$ red). The fluorescence emission shift from red to green indicated the loss of membrane potential. The results indicated that the isoflurane-induced apoptosis was associated with the loss of MMP in the neuronal cells. Flow cytometric analysis of calcein AM and cobalt illustrated that treatment with isoflurane induced an increase the opening of mPTPs in the neuronal cells (Fig. 2B, peak 2) compared with the untreated cells (Fig. 2B, peak 1), as evidenced by the right shift of the curve. We used the fluorescent dye, DCF-DA, to measure the ROS content in the neuronal cells following treatment with isoflurane. As shown in Fig. 2C, isoflurane directly induced an increase in fluorescence intensity in the neuronal cells $(48.6 \%)$ as compared with the untreated cells $(16.2 \%$; $\mathrm{P}<0.05)$. Furthermore, we evaluated the antioxidant enzyme activity of CAT and SOD and found that the levels of CAT and SOD were significantly decreased in the isoflurane-treated neuronal cells $(\mathrm{P}<0.05)$ (Fig. 2D and E). We then examined the cellular ATP levels of the isoflurane-treated neuronal cells and the untreated cells using an ATP-based luminescent assay. The untreated cells had 2-fold higher total cellular ATP levels compared with the isoflurane-treated cells $(\mathrm{P}<0.05)($ Fig. 2F). Furthermore, we observed a decrease in the intracellular calcium ion concentration in the isoflurane-treated neuronal cells (Fig. 2G).

RESV protects neuronal cells against isoflurane-induced apoptosis. Following treatment with isoflurane, the neuronal cells were cultured in the presence of increasing concentrations of RESV $(50,100$ and $200 \mu \mathrm{M})$ for $24 \mathrm{~h}$. This led to an increase in cell viability in a concentration-dependent manner (Fig. 1A). Co-treatment of the neuronal cells with isoflurane and RESV reduced isoflurane-induced cell death in a concentration-dependent manner, as evidenced by comet assay and TUNEL assay (Fig. 1B and C). Subsequently, we investigated the changes in 
$\mathbf{A}$

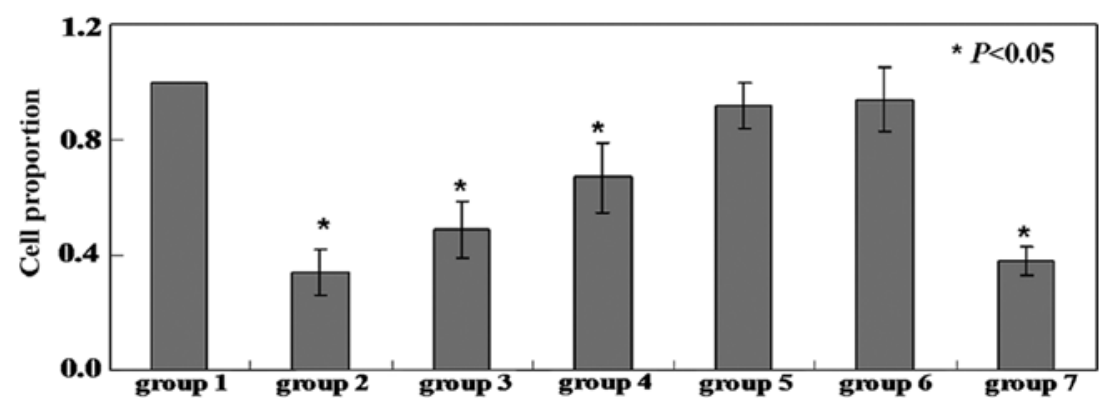

B
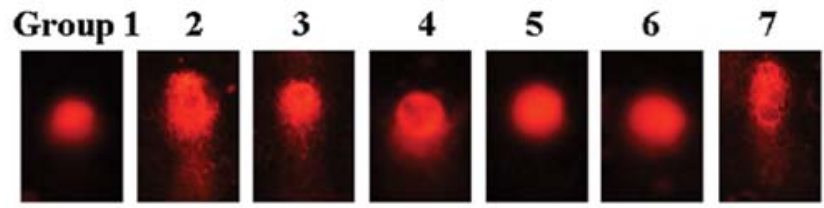

C
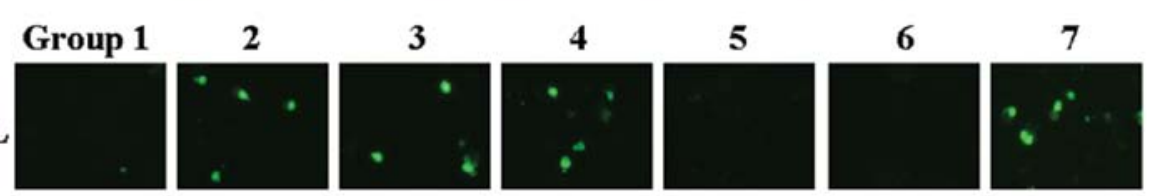

DAPI
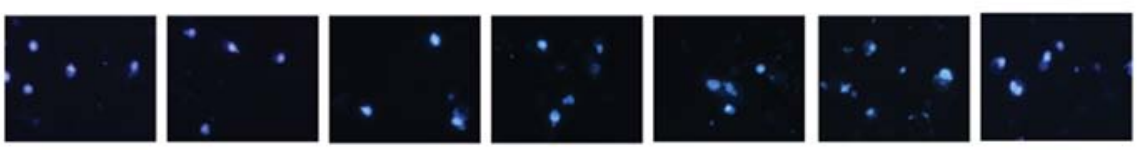

Merge
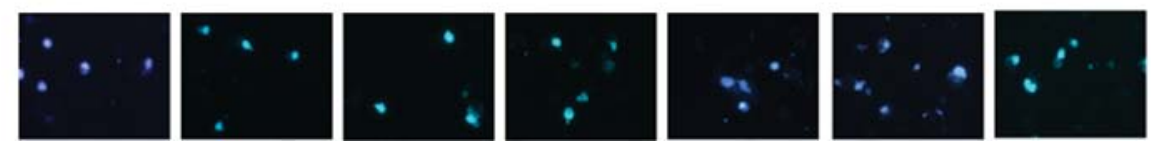

D
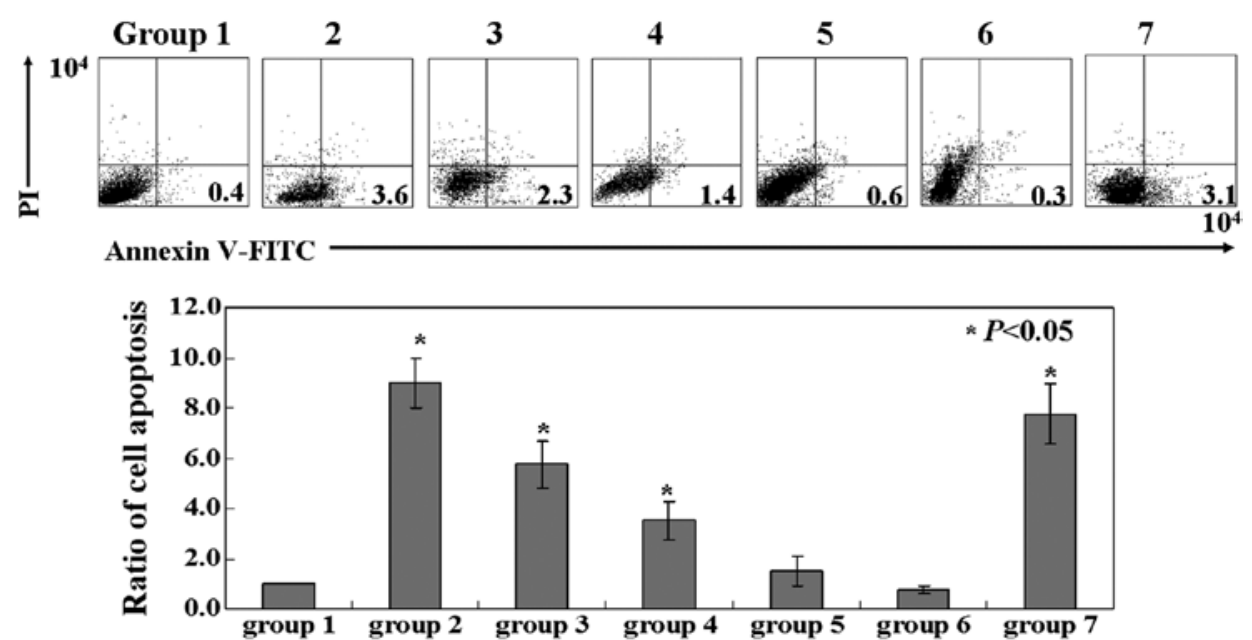

$\mathbf{E}$

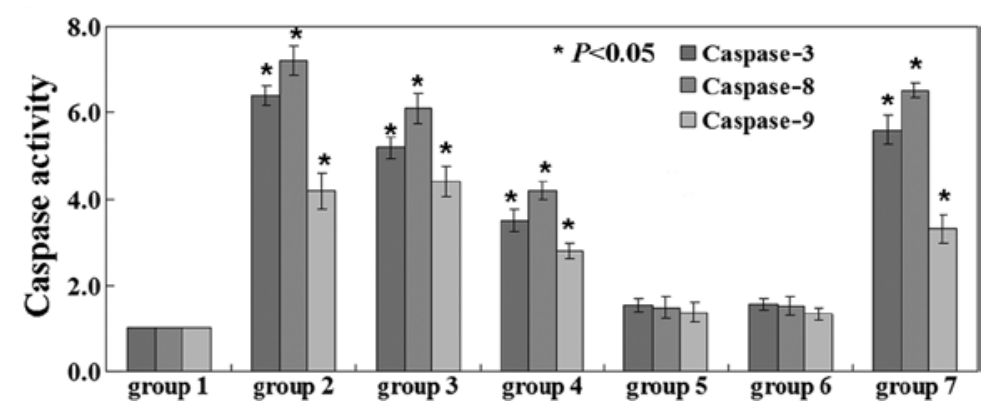

Figure 1. Effects of resveratrol (RESV) and isoflurane on neuronal cells. (A) Neuronal cells were seeded in quadruplex in 96-well dishes at a density of 1,500 cells/well and treated as described in 'Materials and methods'. The proliferation rate of the cells was then measured by MTT assay. (B) DNA damage in neuronal cells was determined by comet assay. (C) Representative TUNEL staining images of neuronal cells following treatment. Apoptotic cells with DNA fragmentation were stained positively as green nuclei. (D) The proportion of apoptotic cells (early apoptosis) was determined by double staining with Annexin V/ FITC and propidium iodide following treatment. (E) The activity of caspase- $3,-8$ and -9 was detected in each group. Experiments were performed in triplicate and were repeated 3 times. Group 1, control; group $2,2 \%$ isoflurane for $6 \mathrm{~h}$; group 3, RESV $50 \mu \mathrm{M}$ for $24 \mathrm{~h}+2 \%$ isoflurane for $6 \mathrm{~h}$; group 4 , RESV $100 \mu \mathrm{M}$ for $24 \mathrm{~h}+2 \%$ isoflurane for $6 \mathrm{~h}$; group 5, RESV $200 \mu \mathrm{M}$ for $24 \mathrm{~h}+2 \%$ isoflurane for $6 \mathrm{~h}$; group 6 , butin $10 \mu \mathrm{g} / \mathrm{ml}$ for $24 \mathrm{~h}+2 \%$ isoflurane for $6 \mathrm{~h}$; group 7 , RESV $200 \mu \mathrm{M}$ for $24 \mathrm{~h}+$ siRNA AKT for $24 \mathrm{~h}+2 \%$ isoflurane for $6 \mathrm{~h}$. 

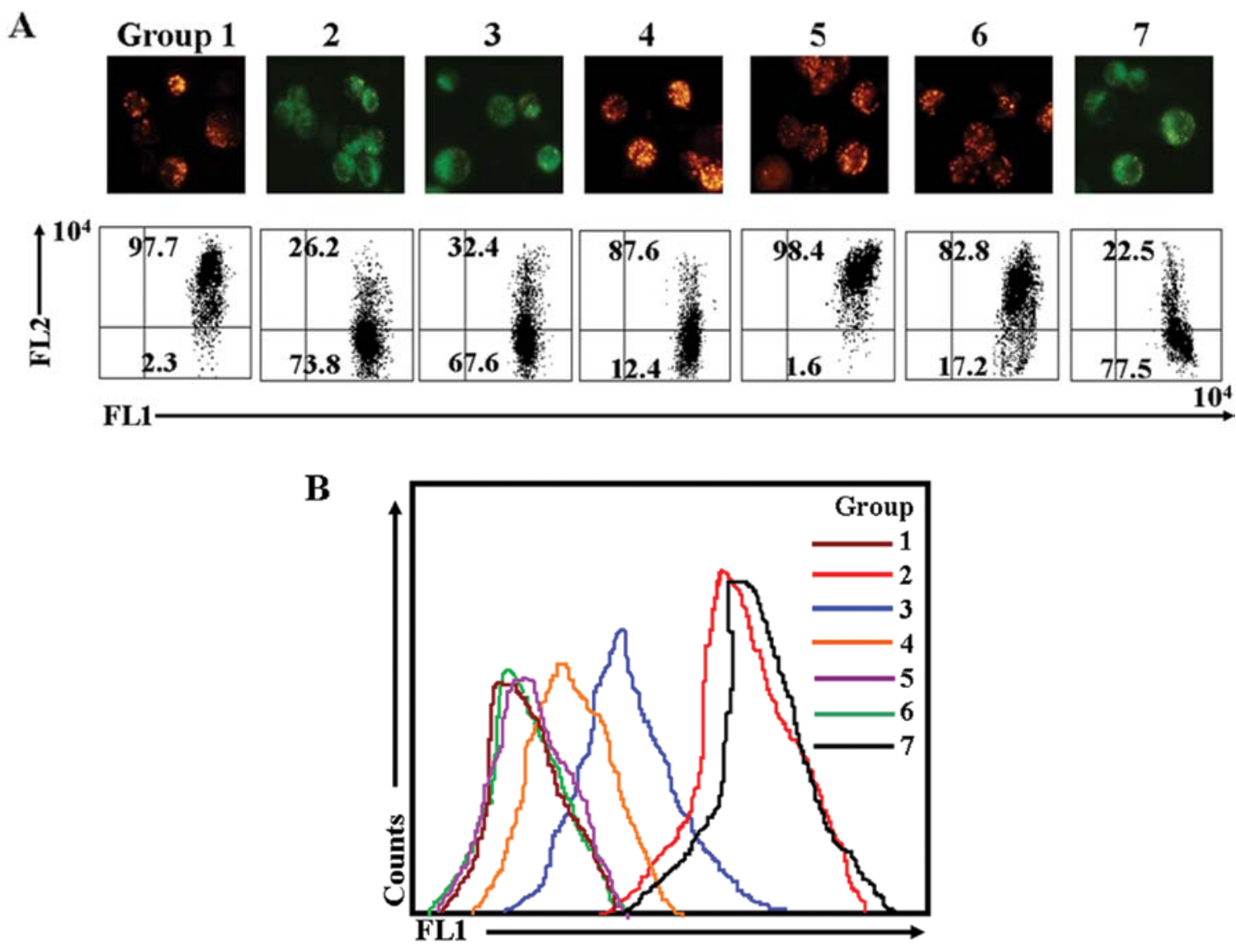

C
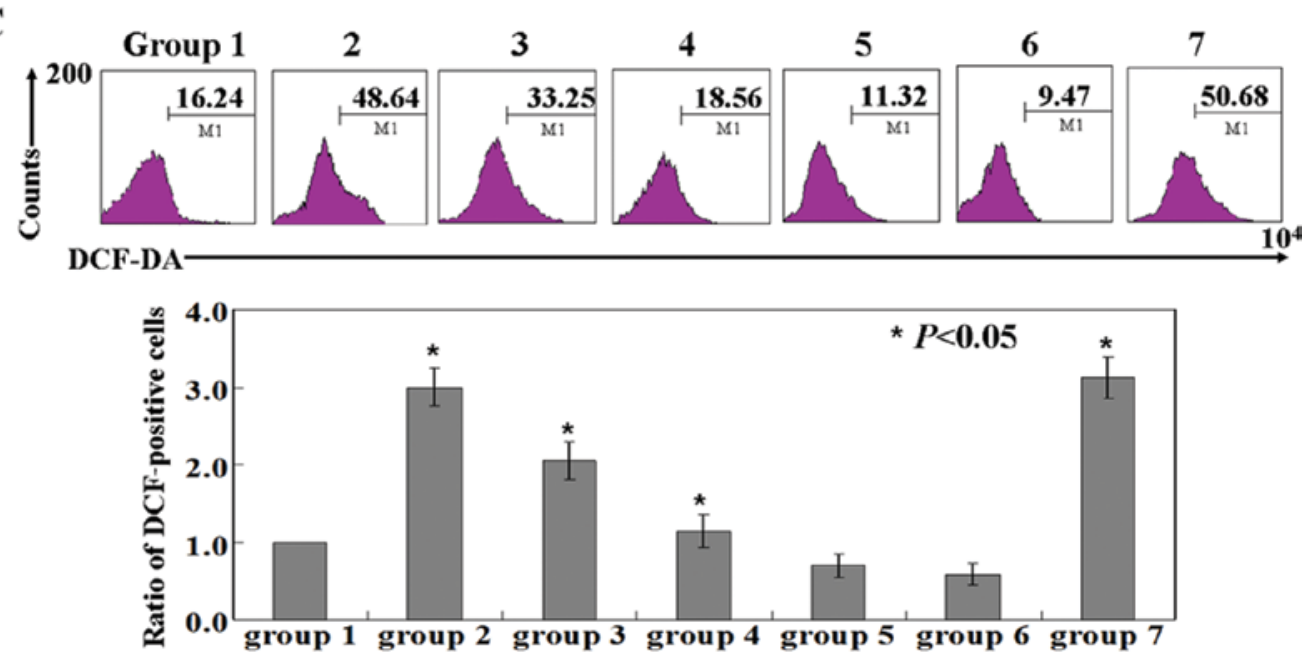

D

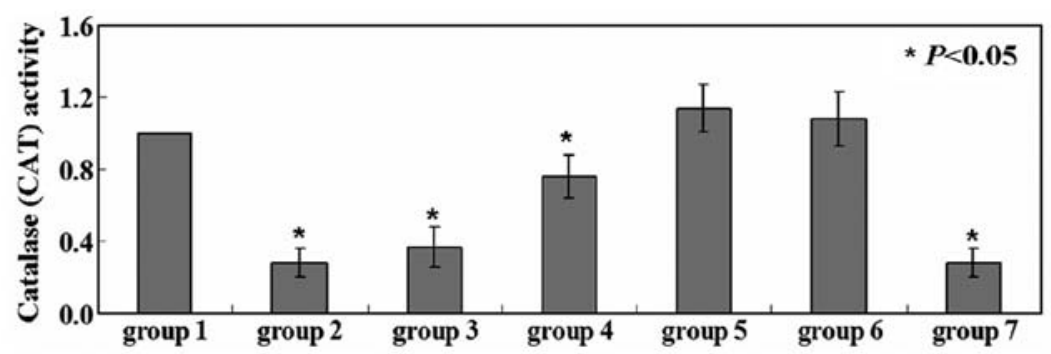

Figure 2. Mitochondrial changes in neuronal cells following treatment with resveratrol (RESV) and isoflurane. (A) Following treatment, cells were plated in 6-well culture plates for $24 \mathrm{~h}$. Mitochondrial membrane potential was then analyzed by immunofluorescence and flow cytometry. (B) Flow cytometric analysis revealed changes in calcein levels in the mitochondria of neuronal cells stained with calcein acetoxymethyl (AM) ester or calcein AM plus cobalt, which indicates the opening of mitochondrial permeability transition pores. (C) Cells were dispensed in a 10 -cm culture dish at a density of $1 \times 10^{6}$ cells/well and treated as described in 'Materials and methods'. The DCF-positive cells (reactive oxygen species production) were then detected using a FL1 signal detector $(525 \mathrm{~nm})$ using a FACSCalibur. (D) Catalase activity was assayed based on the disappearance of $\mathrm{H}_{2} \mathrm{O}_{2}$ at $240 \mathrm{~nm}$. 
$\mathbf{E}$

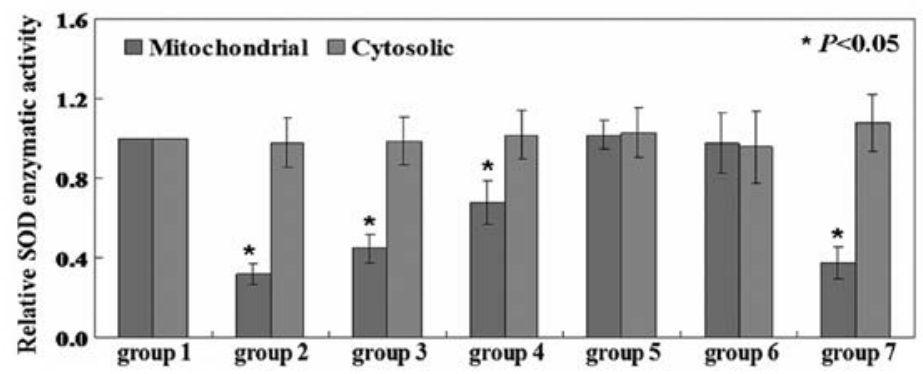

$\mathbf{F}$

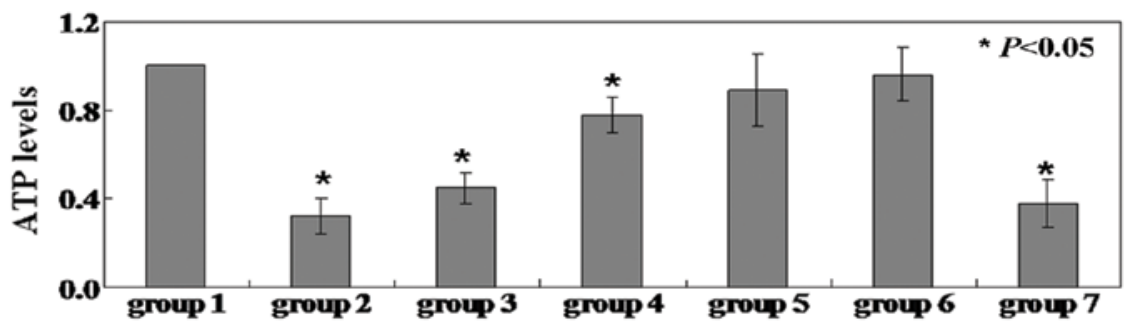

G

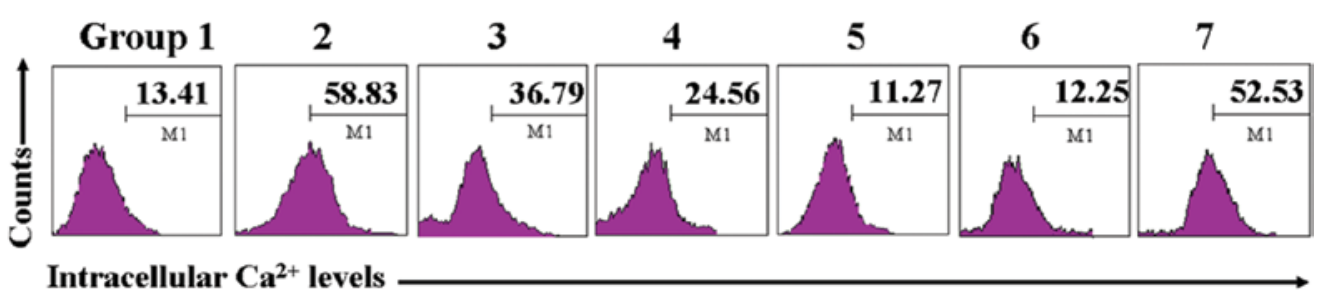

Figure 2. Continued. (E) Mitochondrial and cytosolic fractions were isolated as described in 'Materials and methods'. The superoxide dismutase enzymatic activity in each fraction was measured and normalized as a ratio relative to the control activity. (F) ATP levels were measured in the indicated cells at $24 \mathrm{~h}$ using the ATP Determination kit. (G) Following treatment, cells were labeled with the fluorescent probe Fluo-4-AM. Ca ${ }^{2+}$ levels were detected by flow cytometry. Group 1, control; group 2, $2 \%$ isoflurane for $6 \mathrm{~h}$; group 3, RESV $50 \mu \mathrm{M}$ for $24 \mathrm{~h}+2 \%$ isoflurane for $6 \mathrm{~h}$; group 4, RESV $100 \mu \mathrm{M}$ for $24 \mathrm{~h}+2 \%$ isoflurane for $6 \mathrm{~h}$; group 5, RESV $200 \mu \mathrm{M}$ for $24 \mathrm{~h}+2 \%$ isoflurane for $6 \mathrm{~h}$; group 6, butin $10 \mu \mathrm{g} / \mathrm{ml}$ for $24 \mathrm{~h}+2 \%$ isoflurane for $6 \mathrm{~h}$; group 7 , RESV $200 \mu \mathrm{M}$ for $24 \mathrm{~h}+\operatorname{siRNA}$ AKT for $24 \mathrm{~h}+2 \%$ isoflurane for $6 \mathrm{~h}$.

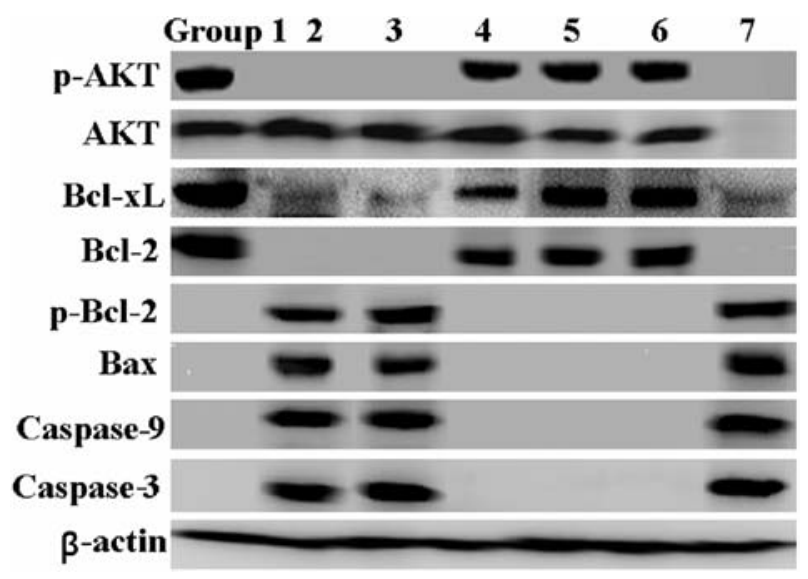

Figure 3. Effects of resveratrol and isoflurane on mitochondrial apoptosisrelated proteins. Cellular protein was isolated from the neuronal cells following treatment for $24 \mathrm{~h}$. Western blot analysis was then performed to detect AKT, Bcl-xl, Bcl-2, Bax, phosphorylated (p)-AKT, phosphorylated (p)-Bcl-2, actived caspase-9 and caspase- 3 proteins using respective specific antibodies. $\beta$-actin was used as an internal control. Group 1, control; group 2, $2 \%$ isoflurane for $6 \mathrm{~h}$; group 3, RESV $50 \mu \mathrm{M}$ for $24 \mathrm{~h}+2 \%$ isoflurane for $6 \mathrm{~h}$; group 4 , RESV $100 \mu \mathrm{M}$ for $24 \mathrm{~h}+2 \%$ isoflurane for $6 \mathrm{~h}$; group 5, RESV $200 \mu \mathrm{M}$ for $24 \mathrm{~h}+2 \%$ isoflurane for $6 \mathrm{~h}$; group 6 , butin $10 \mu \mathrm{g} / \mathrm{ml}$ for $24 \mathrm{~h}+2 \%$ isoflurane for $6 \mathrm{~h}$; group 7 , RESV $200 \mu \mathrm{M}$ for $24 \mathrm{~h}+$ siRNA AKT for $24 \mathrm{~h}+2 \%$ isoflurane for $6 \mathrm{~h}$.

plasma membrane asymmetry (using Annexin V and PI double staining) to quantify the population of dead cells. In the cells treated with RESV and isoflurane, the apoptotic ratio was 1.5-6-fold lower than that of the cells treated with isoflurane alone $(\mathrm{P}<0.05)$ (Fig. 1D). The activity of caspase-3, -8 and -9 was significantly decreased in the RESV- and isoflurane-treated cells compared with the isoflurane-treated cells (Figs. 1E and 3). Hence, we further investigated the effects of RESV on isofluraneinduced changes in mitochondrial function and morphology. Co-treatment with RESV almost completely prevented the isoflurane-induced loss of MMP (Fig. 2A). We also found that treatment with RESV led to a decrease in the isoflurane-induced opening of mPTPs (Fig. 2B, peak 3-5). When DCF-DA was used as a ROS-sensitive fluorescence indicator, the accumulation of ROS in the neuronal cells treated with isoflurane was markedly downregulated by RESV $(\mathrm{P}<0.05)$ (Fig. 2C). The presence of RESV abrogated the decreased levels of CAT and SOD in the isoflurane-treated neuronal cells $(\mathrm{P}<0.05)$ (Fig. 2D and $\mathrm{E})$. As expected, RESV also increased ATP levels and the intracellular calcium ion concentration in the isoflurane-treated neuronal cells $(\mathrm{P}<0.05)$ (Fig. 2F and G). Butin was used as a positive control (Figs. 1 and 2).

Role of the Akt signaling pathway in mediating the protective effects of RESV against isoflurane-induced cytotoxicity. In the present study, we examined the roles of related signaling molecules in mediating isoflurane-induced neuronal death and the protective effects of RESV in neuronal cells by western 
blot analysis. As shown in Fig. 3, p-AKT was downregulated by isoflurane and the levels of total AKT showed no changes. However, p-AKT levels were restored following treatment with RESV. By contrast, the protective effects of RESV were markedly diminished by specific siRNA targeting AKT (Figs. 1 and 2). In addition, we found that butin inhibited the activation of the mitochondrial-dependent apoptotic pathway induced by isoflurane.

\section{Discussion}

The results of the present study demonstrate that RESV effectively protects neuronal cells from isoflurane-induced cytotoxicity by activating the Akt signaling pathway. Anesthesia has been associated with widespread apoptotic neurodegeneration in the neonatal rat brain with persistent functional neurocognitive impairment, exemplified by impaired memory formation (29,30). Isoflurane, a halogenated volatile anesthetic, is frequently used in pediatric general anesthesia and is particularly useful for maintaining a surgical plane of anesthesia for several hours (10). Isoflurane has been shown to induce widespread cerebral neuroapoptosis in neonatal rat pups with subsequent long-term neurocognitive impairment of the animals (31). A previous study also showed that the common inhalation anesthetic, isoflurane, may induce neurotoxicity in vitro (32). In the present study, we successfully established a model of isoflurane-induced apoptosis using neuronal cells, as evidenced by the activation of caspase- 3 and caspase-9.

Although the underlying molecular mechanisms of neurotoxicity are not yet completely understood, mitochondrial dysfunction, altered calcium homeostasis and apoptosis-related proteins have been implicated. A previous study demonstrated that isoflurane induces the release of calcium from the endoplasmic reticulum (ER) in cerebrocortical and hippocampal neurons (33). In this study, we confirmed a decrease in the intracellular calcium ion concentration in isoflurane-treated neuronal cells. These findings suggest that isoflurane induces cellular apoptosis by facilitating the release of calcium from cells. Wei et al (34) reported that isoflurane induced cytotoxicity, which was characterized by nuclear condensation and fragmentation and the activation of caspase- 3 and -9 , by affecting the $\mathrm{Bcl}-2 / \mathrm{Bax}$ ratio. We also observed changes in the levels of $\mathrm{Bcl}-2$ and $\mathrm{Bax}$ in neuronal cells following treatment with isoflurane.

RESV has gained considerable attention due to its potential cancer chemopreventive and anticancer properties (35). In addition, RESV has the potential to control atherosclerosis, heart disease, arthritis and autoimmune disorders (36). RESV scavenges superoxide anions generated from the rat forebrain mitochondria in a concentration dependent manner (37). In the present study, we also confirmed treatment with RESV reversed the production of ROS scavenged ROS that were produced. While SOD contributes to reducing the burden of intracellular ROS, previous studies have shown that SOD plays an important role in neuronal cells against oxidant-induced mitochondrial oxidative stress and cytotoxicity $(38,39)$. Consistent with the results from previous studies, our results confirmed that RESV increased the levels of CAT and SOD in the isoflurane-treated neuronal cells.
Earlier studies have shown that RESV alters the activity of PI3K/Akt signaling molecules (40-44), which are regulated by phosphorylation. We found that the treatment of neuronal cells with RESV alone or RESV plus isoflurane resulted in Akt activation. The protective effects of RESV were markedly diminished by specific siRNA targeting AKT. These results indicate that RESV effectively protects neuronal cells from isoflurane-induced cytotoxicity by activating the Akt signaling pathway.

In conclusion, the present study provides strong evidence that RESV positively controls neurotoxicity triggered by isoflurane in vitro. Experiments using cell cultures revealed that RESV acted, at least in part, by activating the Akt signaling pathway. These findings provide further support for current clinical trials aimed at assessing the beneficial effects of RESV administration against isoflurane-induced neurodegeneration.

\section{Acknowledgements}

We thank Dr Li Ming-Yu for carefully proofreading the manuscript and providing valuable comments.

\section{References}

1. Moonesinghe SR, Mythen MG and Grocott MP: High-risk surgery: epidemiology and outcomes. Anesth Analg 112: 891-901, 2011.

2. Weiser TG, Regenbogen SE, Thompson KD, et al: An estimation of the global volume of surgery: a modelling strategy based on available data. Lancet 372: 139-144, 2008.

3. Wei H, Liang G, Yang H, et al: The common inhalational anesthetic isoflurane induces apoptosis via activation of inositol 1,4,5-trisphosphate receptors. Anesthesiology 108: 251-260, 2008.

4. Loop T and Priebe HJ: Costs of anaesthesia. Eur J Anaesthesiol 22: $162,2005$.

5. Fournier N, Ducet G and Crevat A: Action of cyclosporine on mitochondrial calcium fluxes. J Bioenerg Biomembr 19: 297-303, 1987.

6. Jevtovic-Todorovic V, Hartman RE, Izumi Y, et al: Early exposure to common anesthetic agents causes widespread neurodegeneration in the developing rat brain and persistent learning deficits. J Neurosci 23: 876-882, 2003.

7. Wang S, Peretich K, Zhao Y, et al: Anesthesia-induced neurodegeneration in fetal rat brains. Pediatr Res 66: 435-440, 2009.

8. Winegar BD and Yost CS: Volatile anesthetics directly activate baseline $\mathrm{S} \mathrm{K}^{+}$channels in Aplysia neurons. Brain Res 807: 255-262, 1998.

9. Talley EM and Bayliss DA: Modulation of TASK-1 (Kcnk3) and TASK-3 (Kcnk9) potassium channels: volatile anesthetics and neurotransmitters share a molecular site of action. J Biol Chem 277: 17733-17742, 2002.

10. Franks NP: Molecular targets underlying general anesthesia. $\mathrm{Br}$ J Pharmacol 147 (Suppl 1): S72-S81, 2006.

11. Loepke AW, McCann JC, Kurth C and McAuliffe JJ: The physiologic effects of isoflurane anesthesia in neonatal mice. Anesth Analg 102: 75-80, 2006.

12. Fulda S, Galluzzi L and Kroemer G: Targeting mitochondria for cancer therapy. Nat Rev Drug Discov 9: 447-464, 2010.

13. Csiszar A, Labinskyy N, Pinto JT, et al: Resveratrol induces mitochondrial biogenesis in endothelial cells. Am J Physiol Heart Circ Physiol 297: H13-H20, 2009.

14. Pervaiz S: Resveratrol: from grapevines to mammalian biology. FASEB J 17:1975-1985, 2003.

15. Frémont L: Biological effects of resveratrol. Life Sci 66: 663-673, 2000.

16. Wang Q, Xu J, Rottinghaus GE, et al: Resveratrol protects against global cerebral ischemic injury in gerbils. Brain Res 958: 439-447, 2002. 
17. West T, Atzeva M and Holtzman DM: Pomegranate polyphenols and resveratrol protect the neonatal brain against hypoxic-ischemic injury. Dev Neurosci 29: 363-372, 2007.

18. Ates O, Cayli S, Altinoz E, et al: Effects of resveratrol and methylprednisolone on biochemical, neurobehavioral and histopathological recovery after experimental spinal cord injury. Acta Pharmacol Sin 27: 1317-1325, 2006.

19. Kaplan S, Bisleri G, Morgan JA, et al: Resveratrol, a natural red wine polyphenol, reduces ischemia-reperfusion-induced spinal cord injury. Ann Thorac Surg 80: 2242-2249, 2005.

20. Parker JA, Arango M, Abderrahmane S, et al: Resveratrol rescues mutant polyglutamine cytotoxicity in nematode and mammalian neurons. Nat Genet 37: 349-350, 2005.

21. Markaryan A, Nelson EG, Tretiakova M and Hinojosa R: Technical report: immunofluorescence and TUNEL staining of celloidin embedded human temporal bone tissues. Hear Res 241: 1-6, 2008.

22. Hurst PR, Mora JM and Fenwick MA: Caspase-3, TUNEL and ultrastructural studies of small follicles in adult human ovarian biopsies. Hum Reprod 21: 1974-1980, 2006.

23. Rajagopalan R, Ranjan S and Nair CK: Effect of vinblastine sulfate on gamma-radiation-induced DNA single-strand breaks in murine tissues. Mutat Res 536: 15-25, 2003.

24. Singh NP: Microgels for estimation of DNA strand breaks, DNA protein crosslinks and apoptosis. Mutat Res 455: 111-127, 2000.

25. Zhang Y, Dong Y, Xu Z and Xie Z: Propofol and magnesium attenuate isoflurane-induced caspase-3 activation via inhibiting mitochondrial permeability transition pore. Med Gas Res 2: 20, 2012.

26. Chang HC, Lin KH, Tai YT, et al: Lipoteichoic acid-induced TNF- $\alpha$ and IL- 6 gene expressions and oxidative stress production in macrophages are suppressed by ketamine through downregulating Toll-like receptor 2-mediated activation of ERK1/2 and NFKB. Shock 33: 485-492, 2010.

27. Aebi H: Catalase in vitro. Methods Enzymol 105: 121-126, 1984.

28. Thornberry NA: Caspases: key mediators of apoptosis. Chem Biol 5: R97-R103, 1998

29. Hansen HH, Briem T, Dzietko M, et al: Mechanisms leading to disseminated apoptosis following NMDA receptor blockade in the developing rat brain. Neurobiol Dis 16: 440-453, 2004.

30. Lu LX, Yon JH, Carter LB and Jevtovic-Todorovic V: General anesthesia activates BDNF-dependent neuroapoptosis in the developing rat brain. Apoptosis 11: 1603-1615, 2006.
31. Quinn JJ,Loya F, Ma QD and Fanselow MS: Dorsal hippocampus NMDA receptors differentially mediate trace and contextual fear conditioning. Hippocampus 15: 665-674, 2005.

32. Xie Z, Dong Y, Maeda U, et al: The common inhalation anesthetic isoflurane induces apoptosis and increases amyloid beta protein levels. Anesthesiology 104: 988-994, 2006.

33. Kindler $\mathrm{CH}$, Eilers H, Donohoe P, et al: Volatile anesthetics increase intracellular calcium in cerebrocortical and hippocampal neurons. Anesthesiology 90: 1137-1145, 1999.

34. Wei H, Kang B, Wei W, et al: Isoflurane and sevoflurane affect cell survival and BCL-2/BAX ratio differently. Brain Res 1037: 139-147, 2005.

35. Baur JA and Sinclair DA: Therapeutic potential of resveratrol: the in vivo evidence. Nat Rev Drug Discov 5: 493-506, 2006.

36. Yoshida Y, Shioi T and Izumi T: Resveratrol ameliorates experimental autoimmune myocarditis. Circ J 71: 397-404, 2007.

37. Zini R, Morin C, Bertelli A, et al: Effects of resveratrol on the rat brain respiratory chain. Drugs Exp Clin Res 25: 87-97, 1999.

38. Ookawara $\mathrm{T}$, Imazeki $\mathrm{N}$, Matsubata $\mathrm{O}$, et al: Tissue distribution of immunoreactive mouse extracellular superoxide dismutase Am J Physiol 275: 840-847, 1998.

39. Hinerfeld D, Traini MD, Weinberger RP, et al: Endogenous mitochondrial oxidative stress: neurodegeneration, proteomic analysis, specific respiratory chain defects, and efficacious antioxidant therapy in superoxide dismutase 2 null mice. J Neurochem 88: 657-667, 2004.

40. Aziz MH, Nihal M, Fu VX, et al: Resveratrol-caused apoptosis of human prostate carcinoma LNCaP cells in mediated via modulation of phosphatidilinositol 3'-kinase/Akt pathway and Bcl-2 family proteins. Mol Cancer Ther 5: 1335-1341, 2006.

41. Pozo-Guisado E, Merino JM, Mulero-Navarro S, et al: Resveratrol-induced apoptosis in MCF-7 human breast cancer cells involves a caspase-independent mechanism with downregulation of Bcl-2 and NF-kappaB. Int J Cancer 115: 74-84, 2005.

42. Alkhalaf $M$ : Resveratrol-induced growth inhibition in MDA-MB-231 breast cancer cells is associated with mitogen-activated protein kinase signaling and protein translation. Eur J Cancer Pre 16: 334-341, 2007.

43. She QB, Bode AM, Ma WY, et al: Resveratrol-induced activation of $\mathrm{p} 53$ and apoptosis is mediated by extracellular-signal-regulated protein kinase and p38 kinase. Cancer Res 61: 1604-1610, 2001.

44. She QB, Huang C, Zhang Y and Dong Z: Involvement of c-jun $\mathrm{NH}(2)$-terminal kinases in resveratrol-induced activation of p53 and apoptosis. Mol Carcinog 33: 244-250, 2002. 